\title{
Seroepidemiology of Bordetella pertussis Infection in Fresh College Students in Iran: A Multicenter Study
}

\author{
Iraj Sedighi ${ }^{1}$; Hamid Rahimi ${ }^{2}$; Monir Sadat Emadoleslami ${ }^{3}$; Alireza Fahimzad ${ }^{4}$; Firuzeh \\ Hosseini ${ }^{1}$; Mandana Afsharian ${ }^{5}$; Ahmad Akbarzadeh ${ }^{6}$; Homayon Vahedi ${ }^{3}$; Ali Amanati ${ }^{4}$; \\ Mansour Rezaei ${ }^{5}$; Keyghobad Ghadiri ${ }^{5,}$ \\ ${ }_{2}^{1}$ Department of Pediatrics, Hamadan University of Medical Sciences, Hamadan, IR Iran \\ ${ }_{3}^{2}$ Department of Infectious Diseases, Infectious Diseases and Tropical Medicine Research Center, Isfahan University of Medical Sciences, Isfahan, IR Iran \\ 3 Department of Pediatrics, Isfahan University of Medical Sciences, Isfahan, IR Iran \\ ${ }_{5}^{4}$ Department of Pediatrics, Pediatric Infectious Research Center, Shahid Beheshti University of Medical Sciences, Tehran, IR Iran \\ 5 Department of Pediatrics, Nosocomial Infections Research Center, Kermanshah University of Medical Sciences, Kermanshah, IR Iran \\ 6 Department of Pediatrics, Semnan University of Medical Siences, Semnan, IR Iran \\ *Corresponding author: Keyghobad Ghadiri, Department of Pediatrics, Nosocomial Infections Research Center, School of Medicine, Kermanshah University of Medical Sciences, \\ Kermanshah, IR Iran. Tel: + 98-9183310419, Fax: + 98-8314262252, E-mail: k_ghadiri@yahoo.com
}

Received: January 1, 2014; Accepted: January 10, 2014

\begin{abstract}
Background: Pertussis is a highly communicable, vaccine-preventable respiratory disease; which may circulate even in populations with high vaccination coverage. Although frequent, but it is often underestimated as a cause of prolonged cough illness in both children and adults. Without boosting, the protection of the childhood vaccination would be minimal after 10 years. The need for adult booster vaccination depends on the national epidemiology.

Objectives: The aim of this study was to evaluate the seroepidemiological incidence of Pertussis in fresh college students in four majors.

Patients and Methods: In a cross sectional multicenter study, blood samples were obtained from 1617 junior students of four universities. None had received Pertussis booster vaccine in the preceding 10 years. Serum immunoglobulin G (IgG) antibody for Pertussis toxin antigen was measured. Some social and demographic determinants including age, sex and number of family members were recorded.

Results: The mean age of participants was $19.64 \pm 2.1$ years; positive anti Pertussis toxin IgG levels (by cut point of $94 \mathrm{U} / \mathrm{mL}$ ) was detected in 31.6\%. Positivity rate was associated with sex but not with age or residential area.

Conclusions: Pertussis continues to challenge medical and public health professionals. Recent reports of increases in the prevalence and incidence may be because of the limited time of protection of childhood vaccination. Our study can serve as one of the scarce populationbased reports from developing countries. A universal cut point should be determined for diagnosis of seropositivity, and a booster of a cellular vaccine is recommended in adolescence.
\end{abstract}

Keywords:Bordetella pertussis; Antibodies; Prevention and Control; Young Adults

\section{Background}

Pertussis is caused by Bordetella pertussis, and is a highly communicable, acute bacterial infection of the respiratory tract $(1,2)$. This organism is a gram-negative, fastidious, pleomorphic bacillus that continues to cause a global public health problem and can lead to a fatal illness in young infants (3-7). Neither its infection nor its vaccination provides permanent immunity (8-10). Therefore, In spite of high vaccination coverage in childhood, this disease remains a cause of substantial morbidity in the world (8-15). It is the only disease with universal childhood vaccination but with an escalating trend in the US $(16,17)$.

\section{Objectives}

Adults and adolescents with mild or subclinical in- fections are important sources of Pertussis for Infants and young children $(6,7,17-19)$. Most related reports are from high-income communities, and limited experience exists from low- and middle-income countries. The current study aimed to report the prevalence of Pertussis in a sample of Iranian young adults.

\section{Patients and Methods}

\subsection{Setting}

This multicenter study was conducted in 2007 in four universities located in four provinces in Iran. The universities were Isfahan University of Medical Sciences in Isfahan, Shahid Beheshti University of Medical Sciences

Implication for health policy/practice/research/medical education:

Identifying the seroprevalence and recent infection with pertussis in medical students.

Copyright @ 2014, Infectious Diseases and Tropical Medicine Research Center. This is an open-access article distributed under the terms of the Creative Commons Attribution License, which permits unrestricted use, distribution, and reproduction in any medium, provided the original work is properly cited. 
in Tehran, Kermanshah University of Medical Sciences in Kermanshah, and Hamadan University of Medical Sciences in Hamadan. Students from different parts of the country are accepted in universities after passing a national entrance examination, thus our study populations were considered to be nationally representative.

\subsection{Study Population}

At the beginning of the academic year of 2007, all newly accepted students to the aforementioned universities were enrolled in this study on the first day of their entrance to the university. Those students with history of receiving intravenous immunoglobulin (IVIG) infusion, respiratory illnesses during the previous month or with immunodeficiencies were not included into the study. In the case of lysis or lipemic status in obtained serum samples, the samples were excluded from study. The study was approved by the Research \& Ethics Committees of the four collaborating universities. All students signed informed consent.

\subsection{Laboratory Tests}

All serum samples were screened for immunoglobulin G (IgG) antibodies against Bordetella pertussis toxin (PT) by enzyme-linked immunosorbant assay (ELISA) with using IBL-AMERICA Bordetella pertussis IgG Antibody ELISA Test Kit (Minnesota, USA). All tests were performed in the laboratory of the Infectious Diseases Research Center, affiliated to Isfahan University of Medical Sciences, Isfahan, Iran.

\subsection{Statistical Analysis}

We considered various cut-off points of anti-Pertussis
IgG (anti-PT IgG) to determine the prevalence of Pertussis in the study samples. Two-tailed Chi-square test was used to find statistically significant differences based on various anti-PT IgG cut-off points. We also employed Chi-square for trend to investigate the linear incremental trend in these cut-off points. Data analysis was conducted by SPSS software package version 13.0 (SPSS Inc., Chicago, Illinois, USA). The significance level was set at $\mathrm{P}<0.05$.

\section{Results}

Overall, 1617 freshman students of four universities of medical sciences in Iran were studied. The mean age was $19.64 \pm 2.1$ years with a range of 17 to 38 years. Distribution of age subgroups was as follows: 1079 (66.9\%) cases were aged under 20 years, 470 (29.1\%) cases were 20 -24 years, 61 (3.8\%) cases were $25-29$ years and $4(0.2 \%)$ cases were more than 30 years. Overall, 980 (60.7\%) students were female and 635 (39.3\%) were male. The mean number of family members was $5.5 \pm 1.8$ (median $=5$ ) with the minimum of 2 and the maximum of 14 . Distribution of family member subgroups was: 498 (31\%) cases $\leq 4$ members, $434(27 \%)$ cases 4-5 members and $676(42 \%)$ cases $>6$ members. The mean serum IgG titer was $66.19 \pm 51.8 \mathrm{U} / \mathrm{mL}$ with the minimum $2 \mathrm{U} / \mathrm{mL}$ and maximum $250 \mathrm{U} / \mathrm{mL}$. The mean of serum IgG titer was $61.97 \pm 52 \mathrm{U} / \mathrm{mL}$ in females and 72.71 $\pm 50 \mathrm{U} / \mathrm{mL}$ in males. Table 1 presents the frequency of sero-positivity of Pertussis according to gender, and Table 2 presents it according to age groups. The prevalence of Pertussis was 37.7\% (609 cases) by considering cut-off point of anti-PT IgG of $80 \mathrm{U} / \mathrm{mL}$, i.e. IgG titer $\geq 80 \mathrm{U} / \mathrm{mL}$, $31.6 \%$ (511 Cases) by cut-off point of $94 \mathrm{U} / \mathrm{mL}$ (14), and $28.4 \%$ (460 Cases) by cut-off point of $100 \mathrm{U} / \mathrm{mL}$ (Table 3).

\begin{tabular}{|c|c|c|c|}
\hline & Female, No. (\%) & Male, No. (\%) & Total, No. (\%) \\
\hline \multicolumn{4}{|c|}{ Cut point $5 \mathrm{U} / \mathrm{mL}$} \\
\hline Positive & $970(60)$ & $626(38.7)$ & $1596(98.7)$ \\
\hline Negative & $12(0.7)$ & $9(0.6)$ & $21(1.3)$ \\
\hline Total & $982(60.7)$ & $635(39.3)$ & $1617(100.0)$ \\
\hline \multicolumn{4}{|c|}{ Cut point $94 \mathrm{U} / \mathrm{mL}$} \\
\hline Positive & $287(17.7)$ & $224(13.9)$ & $511(31.6)$ \\
\hline Negative & $695(43.0)$ & $411(25.4)$ & $1106(68.4)$ \\
\hline Total & $982(60.7)$ & $635(39.3)$ & $1617(100.0)$ \\
\hline \multicolumn{4}{|c|}{ Cut point $100 \mathrm{U} / \mathrm{mL}$} \\
\hline Positive & $260(16.1)$ & $200(12.4)$ & $460(28.4)$ \\
\hline Negative & $722(44.7)$ & $435(26.9)$ & $1157(71.6)$ \\
\hline Total & $982(60.7)$ & $635(39.3)$ & $1617(100.0)$ \\
\hline
\end{tabular}


Sedighi I et al.

Table 2. The Frequency of Anti-Pertussis Sero-Positivity Based on Various Cut Points According to Age Group

\begin{tabular}{|c|c|c|c|c|c|}
\hline & \multicolumn{5}{|c|}{ Age Groups, No. (\%), y } \\
\hline & $<\mathbf{2 0}$ & $20-24$ & $25-29$ & $\geq \mathbf{3 0}$ & Total \\
\hline \multicolumn{6}{|c|}{ Cut Point $5 \mathrm{U} / \mathrm{mL}$} \\
\hline Positive & $1067(66.1)$ & $463(28.7)$ & $59(3.7)$ & $4(0.2)$ & $1593(98.7)$ \\
\hline Negative & $12(0.7)$ & $7(0.4)$ & $2(0.1)$ & $0(0)$ & $21(1.3)$ \\
\hline Total & $1079(66.9)$ & $470(29.1)$ & $61(3.8)$ & $4(0.2)$ & $1614(100)$ \\
\hline \multicolumn{6}{|c|}{ Cut point $94 \mathrm{U} / \mathrm{mL}$} \\
\hline Positive & $335(20.8)$ & $154(9.5)$ & $21(1.3)$ & $1(0.1)$ & $511(31.7)$ \\
\hline Negative & $774(46.1)$ & $316(19.6)$ & $40(2.5)$ & $3(0.2)$ & $1103(68.3)$ \\
\hline Total & $1079(66.9)$ & $470(29.1)$ & $61(3.8)$ & $4(0.2)$ & $1614(100)$ \\
\hline \multicolumn{6}{|c|}{ Cut point $100 \mathrm{U} / \mathrm{mL}$} \\
\hline Positive & $299(18.5)$ & $141(8.7)$ & $19(1.2)$ & $1(0.1)$ & $460(28.5)$ \\
\hline Negative & $780(48.3)$ & $329(20.4)$ & $42(2.6)$ & $3(0.2)$ & $1154(71.5)$ \\
\hline Total & $1079(66.9)$ & $470(29.1)$ & $61(3.8)$ & $4(0.2)$ & $1614(100)$ \\
\hline
\end{tabular}

Table 3. Age, Gender and Number of Family Members in Seropositive Cases According to Different Cut Points

\begin{tabular}{lccccccc}
\hline Cut Point, U/mL & $\begin{array}{c}\text { Seropositive, } \\
\text { No. }(\%)\end{array}$ & $\begin{array}{c}\text { Female, } \\
\text { No. }(\%)\end{array}$ & $\begin{array}{c}\text { Male, } \\
\text { No. }(\%)\end{array}$ & P value & $\begin{array}{c}\text { Number of Family } \\
\text { Members, Mean }\end{array}$ & P value & Age, Mean, y \\
\hline Cut Point 5 & $1596(98.7)$ & 970 & 625 & 0.823 & 5.50 & 0.138 & 19.63 \\
\hline Cut Point 9 & $1507(93.2)$ & 905 & 602 & 0.043 & 5.50 & 0.539 & 19.64 \\
\hline Cut Point 11 & $1448(89.5)$ & 863 & 585 & 0.008 & 5.50 & 0.301 & 19.66 \\
\hline Cut Point 40 & $896(55.4)$ & 491 & 405 & $<0.0001$ & 5.25 & $<0.0001$ & 19.87 \\
\hline Cut Point 50 & $824(51)$ & 456 & 368 & $<0.0001$ & 5.25 & $<0.0001$ & 19.79 \\
\hline Cut Point 80 & $609(37.7)$ & 339 & 270 & 0.001 & 5.35 & 0.004 & 19.72 \\
\hline Cut Point 94 & $511(31.6)$ & 287 & 224 & 0.012 & 5.43 & 0.214 & 19.72 \\
\hline Cut Point 100 & $460(28.4)$ & 260 & 200 & 0.032 & 5.46 & 0.457 & 19.76 \\
\hline
\end{tabular}

\section{Discussion}

We found a considerably high prevalence of university students with positive anti-PT IgG. Given that vaccination against Pertussis leads to short-term increase in antibody level $(7,10,11,20)$, the possibility of false positive titers due to previous vaccination seems to be unlikely. As the age of our cases ranged between 17 to 38 years and according to the national immunization schedule of Iran, they had taken the last booster dose of DTP at the age of 4 to 6 years, the elevated anti PT IgG levels were attributed to recent infection with Bordetella pertussis. Similar to many previous studies $(14,18,21-23)$, we used different cut-off points of anti-PT IgG levels for estimating the prevalence of Pertussis infection. A study in Poland (23) reported the prevalence of Bordetella pertussis infection according to three cut-off points of 40,80 and $100 \mathrm{U} / \mathrm{mL}$, reflecting contact with this bacteria in the previous two, three, and 12 months. In this study, the prevalence was reported $7.2 \%$, $6.6 \%$ and $5.2 \%$, respectively; whereas in our study, the corresponding figures were $55.4 \%, 37.7 \%$ and $28.4 \%$, respectively. The higher prevalence of infection in our study than that of Poland is suggested to be because our study was conducted in October, the beginning of the academic year in Iran, with its previous 5 months being in spring and summer time, which have the highest prevalence of Bordetella pertussis. In a survey in Singapore (24) by using the cut-off point of $5 \mathrm{U} / \mathrm{mL}$, the prevalence of Pertussis infection was $97 \%$ among $18-45$ years old persons. It is similar to the prevalence of $98.7 \%$ documented in our study. In a study in Turkey, seropositivity in cut-off point of $9 \mathrm{U} / \mathrm{mL}$ is reported as $30 \%$, but interestingly at the same cut-off point, $93.2 \%$ of our study population were seropositive. This difference probably comes from the routine use of a cellular Pertussis vaccine in the national immunization program in Turkey instead of the cellular vaccine, which has more efficacy and latency (25). While the specificity of cut-off point of $94 \mathrm{U} / \mathrm{mL}$ for acute infection was estimated 99\% in a study in United States (14), The incidence of acute infection in same cut-off point was $31.6 \%$ in our study. However, by using all cut-off points - except than $5 \mathrm{U} / \mathrm{mL}$ - the prevalence of Pertussis infection was significantly different in terms of gender. In a study among Turkish children (26), IgG titer had no significant correlation 
with the number of family members, but in another study in Cameroon, (27) significant differences are reported in IgG titer of children according to the number of family members. In our study, we found significant differences in anti-PT IgG levels in cut-points of 40, 50, and $80 \mathrm{U} / \mathrm{mL}$. We found clear differences in the prevalence of Bordetella pertussis infection in our study with other reports. A previous study in Iranian young adults was conducted among 424 randomly selected military garrisons, aged 18 to 21 years, in Tehran. By considering a cut point of $20 \mathrm{U} / \mathrm{mL}$, the seropositivity is reported to be $60.6 \%(28)$. The corresponding figure in our study was $74 \%$. Furthermore, a study in Iranian university students was conducted in Hamedan. A number of 163 students were studied, and by considering a cut point of $24 \mathrm{U} / \mathrm{mL}$, the sero-prevalence rate of IgG-PT was $47.67 \%$ (29). It is noteworthy to mention that to have an ideal group for studying the sero-prevalence of IGG-PT, we recruited our study participants at the first day of their entry to university, and before their stay in the crowded environment of dormitories, whereas this point has not been considered in previous studies in Iran. Different cut-off points have been used to determine the seropositivity for Bordeella pertussis; one of the recent recommendations states that a single serum sample showing anti-PT IgG above $100 \mathrm{U} / \mathrm{mL}$ may indicate a recent infection (30). Regardless to the cut-off point used, studies of various countries revealed a substantially high prevalence of infection with Bordetella pertussis among adolescents and young adults.

Although the incidence of Pertussis is reduced in infants and young children - because of the introduction of universal childhood immunization - in countries with high vaccination rates it has been increasing in adolescents and young adults in recent years especially in ages ranging between 35-39 years. An accumulating body of evidence proposes that the current childhood immunization schedule is not efficient and long lasting for eradication of Pertussis, thus a booster dose of a cellular vaccine is recommended in later life. Several scientific consensus statements, as the American Academy of Pediatrics $(31,32)$ have recommended to consider a booster dose in adolescence. The recent recommendations in immunization schedule suggest that adolescents should receive a single dose of Tdap vaccine instead of Td for booster immunization against tetanus, diphtheria, and Pertussis and the preferred age for Tdap immunizations is 11 through 12 years of age (31-38).

Pertussis continues to challenge medical and public health professionals; recent increases in the prevalence and incidence may be because of the limited efficacy and latency of childhood vaccination. Moreover, age-cohort effects, vaccine effectiveness, or changes in testing patterns should be considered. Our study can serve as one of the scarce population-based reports from developing countries. A universal cut-off point should be determined for diagnosis of seropositivity, and a booster of a cellular vaccine is recommended in adolescence.

\section{Acknowledgements}

We acknowledge Kermanshah, Hamadan, Shahid Beheshti and Isfahan Universities of Medical Sciences.

\section{Authors' Contributions}

All authors contributed equally to this research.

\section{Funding/Support}

This research was supported by Kermanshah, Hamadan, Shahid Beheshti and Isfahan Universities of Medical Sciences.

\section{References}

1. James D, Cherry UH. Pertusssis and other Bordetella infections. 6 ed. Vol. 1. Philadelphia: saunders; 2009.

2. Sarah SL, Behrman K, Jenson S. Nelson textbook of pediatrics. 18 ed. Philadelphia: Sanders; 2007.

3. James D. Cherry, Emmanuel Grimprel, Nicole Guiso, Ulrich Heiningerand Jussi Mertsola, Defining Pertussis Epidemiology, Microbiologic and Serologic Perspectives. Pediatr Infect Dis J. 2005;24(5):25-35.

4. de Juanes JR, Gil A, Gonzalez A, Arrazola MP, San-Martin M, Esteban J. Seroprevalence of pertussis antibody among health care personnel in Spain. Eur J Epidemiol. 2004;19(1):69-72.

5. Jackson LA, Cherry JD, Wang SP, Grayston JT. Frequency of serological evidence of Bordetella infections and mixed infections with other respiratory pathogens in university students with cough illnesses. Clin Infect Dis. 2000;31(1):3-6.

6. Greenberg DP. Pertussis in adolescents: increasing incidence brings attention to the need for booster immunization of adolescents. Pediatr Infect Dis J. 2005;24(8):721-8.

7. Aaron M, Wendelboe JG, Michael G, Emmanuel G, David G, Scott $\mathrm{H}$, et al. Transmission of Bordetella pertussis to Young Infants. Pediatr Infect Dis J. 2005;24(6):510-3.

8. Chris A, Morgan M, James D, Cherry PC, Karen L, Evelyn P, et al. Blumberg.A Search for Bordetella pertussis Infection in University Students. Clinic Infect Dis. 1992;14(4):64-71.

9. Zepp F, Knuf M, Habermehl P, Schmitt JH, Rebsch C, Schmidtke P, et al. Pertussis-specific cell-mediated immunity in infants after vaccination with a tricomponent acellular pertussis vaccine. Infect Immun. 1996;64(10):4078-84.

10. Edwards KM. Overview of pertussis: focus on epidemiology, sources of infection, and long term protection after infant vaccination. Pediatr Infect Dis J. 2005;24(6 Suppl):S104-8.

11. Aaron M, Annelies VR, Stefania S. Duration of Immunity Against Pertussis After Natural Infection or Vaccination. Pediatr Infect Dis J. 2005;24(5):58-61.

12. Cherry JD. The epidemiology of pertussis and pertussis immunization in the United Kingdom and the United States: a comparative study. Curr Probl Pediatr. 1984;14(2):1-78.

13. Chiu TF, Lee CY, Lee PI, Lu CY, Lin HC, Huang LM. Pertussis seroepidemiology in Taipei. J Formos Med Assoc. 2000;99(3):224-8.

14. Baughman AL, Bisgard KM, Edwards KM, Guris D, Decker MD, Holland K, et al. Establishment of diagnostic cutoff points for levels of serum antibodies to pertussis toxin, filamentous hemagglutinin, and fimbriae in adolescents and adults in the United States. Clin Diagn Lab Immunol. 2004;11(6):1045-53.

15. Cherry JD, Grimprel E, Guiso N, Heininger U, Mertsola J. Defining pertussis epidemiology: clinical, microbiologic and serologic perspectives. Pediatr Infect Dis J. 2005;24(5 Suppl):S25-34

16. Guinto-Ocampo H, Bennett JE, Attia MW. Predicting pertussis in infants. Pediatr Emerg Care. 2008;24(1):16-20.

17. Elliott E, McIntyre P, Ridley G, Morris A, Massie J, McEniery J, et al National study of infants hospitalized with pertussis in the acellular vaccine era. Pediatr Infect Dis J. 2004;23(3):246-52.

18. Bisgard KM, Pascual FB, Ehresmann KR, Miller CA, Cianfrini C, Jennings CE, et al. Infant pertussis: who was the source? Pediatr 
Infect Dis J. 2004;23(11):985-9.

19. Jeffrey P. Davis, Chief Medical Officer and State Epidemiologist For Communicable Disease. . CDC Pertussis Treatment Guidelines. 2005. Available from: http://www.cdc.gov/mmwr/preview/mmwrhtml/ rr5414al.htm

20. Prevention of pertussis among adolescents: recommendations for use of tetanus toxoid, reduced diphtheria toxoid, and acellular pertussis (Tdap) vaccine. Pediatrics. 2006;117(3):965-78.

21. Lopez AL, Pineda E, Garakian A, Cherry JD. Effect of heat inactivation of serum on Bordetella pertussis antibody determination by enzyme-linked immunosorbent assay. Diagn Microbiol Infect Dis. 1998;30(1):21-4.

22. Trudy M, Kris B, DVM , Gary S. Duration of Immunity Against Pertussis After Natural Infection or vaccination. Pediatr Infect Dis J. 2005;24(5):58-61.

23. de Melker HE, Versteegh FG, Schellekens JF, Teunis PF, Kretzschmar M. The incidence of Bordetella pertussis infections estimated in the population from a combination of serological surveys. J Infect. 2006;53(2):106-13.

24. Wilder-Smith A, Ng S, Earnest A. Seroepidemiology of pertussis in the adult population of Singapore. Ann Acad Med Singapore. 2006;35(11):780-2.

25. Greco D, Salmaso S, Mastrantonio P, Giuliano M, Tozzi AE, Anemona A, et al. A controlled trial of two acellular vaccines and one whole-cell vaccine against pertussis. Progetto Pertosse Working Group. N Engl J Med.1996;334(6):341-8.

26. Inandi T, Guraksin A, Hacialioglu N. Seroprevalence of pertussis among children in Eastern Turkey. Public Health. 2005;119(6):550-5.

27. Stroffolini T, Giammanco A, Chiarini A, Taormina S, Sarzana A, Mazza G, et al. Seroepidemiology of pertussis infection in an urban childhood population in Cameroon. Eur Epidemiol. 1991;7(1):64-7.

28. Izadi M, Afsharpaiman S, Jonaidi Jafari N, Ranjbar R, Gooya MM,
Robat Sarpooshi J, et al. Immunization status of Iranian military recruits against Bordetella pertussis infection (whooping cough). J Infect Dev Ctries. 2011;5(3):224-6.

29. Hashemi SH, Ranjbar M, Hajilooi M, Seif-Rabiei MA, Bolandi M, Moghimi J. Seroprevalence of Immunoglobulin $G$ antibodies against pertussis toxin among asymptomatic medical students in the west of Iran: a cross sectional study. BMC Infect Dis. 2009;9:58.

30. Long SS. In Nelson textbook of Pediatrics.19 ed.USA:Saunders Co;2011.

31. Pichichero ME, Edwards KM, Anderson EL, Rennels MB, Englund JA, Yerg DE, et al. Safety and immunogenicity of six acellular pertussis vaccines and one whole-cell pertussis vaccine given as a fifth dose in four- to six-year-old children. Pediatrics. 2000;105(1):e17922.

32. Report of the America Academy of Pediatrics Commitee on Infectious Diseases. USA: RED BOOK; 2009.

33. ACIP expands Tdap recommendations. An update from the Michigan Department of Community Health. Mich Med. 2011;110(2):22-3.

34. LoMurray K, Sander M. Using the North Dakota Immunization Information System to determine adolescent vaccination rates and uptake. Public Health Rep. 2011;126 Suppl 2:78-86.

35. Lindley MC, Smith PJ, Rodewald LE. Vaccination coverage among U.S. adolescents aged 13-17 years eligible for the Vaccines for Children program, 2009. Public Health Rep. 2011;126 Suppl 2:124-34.

36. Grenfell B. Boosting understanding of pertussis outbreaks. Proc Natl Acad Sci U S A. 2011;108(18):7279-80.

37. Chadambuka A, Chimusoro A, Apollo T, Tshimanga M, Namusisi O, Luman ET. The need for innovative strategies to improve immunisation services in rural Zimbabwe. Disasters. 2012;36(1):161-73.

38. Lutynska A, Wiatrzyk A, Mosiej E, Zawadka M. [Immunization of adolescents and adults as the strategy of improvement of epidemiology of pertussis]. Przegl Epidemiol. 2011;65(1):45-50. 